\title{
Sustainability science demands that we define our terms across diverse disciplines
}

\author{
James Aronson
}

Received: 4 February 2011/Accepted: 8 February 2011/

Published online: 20 February 2011

(C) Springer Science+Business Media B.V. 2011

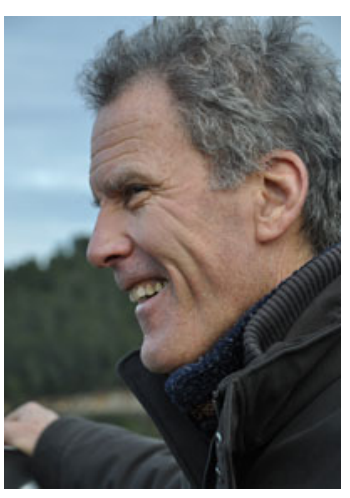

Landscape ecology is an essential part of sustainability science (Forman 1990; Wu 2006, 2010a, b; Naveh 2007; Musacchio 2009, 2011), but so are several other disciplines, some quite disparate. The term includes not only conservation biology, and restoration ecology, but also social and cultural fields like economics, philosophy, sociology, and anthropology. Scientists (and others) who aspire to contribute to sustainability studies and practice urgently need to get our inter-professional, transdisciplinary, civic, and societal acts together, as the saying goes. But can scientists really help societies move towards sustainability, and if so, how? First, we need to develop a shared set of definitions, methods of communication, and analysis, based on concepts tailored to address the core questions in a common language. We also need to learn how to communicate with non-scientists: businessmen and women, journalists, administrators, and the great majority of political leaders and citizens, who tend to have limited-often very limited-contact with the culture of science.

Improving the clarity of the concepts and definitions we habitually use in any given field of science is a necessary precursor to wider discourse and decision-making across disciplinary and professional

J. Aronson ( $\square)$

Centre d'Ecologie Fonctionnelle et Evolutive

(CEFE/CNRS-UMR 5175), Montpellier, France and

Missouri Botanical Garden, St. Louis, MO, USA

e-mail: james.aronson@cefe.cnrs.fr lines. Wu and Hobbs (2007) note that "Good science starts with precise definitions because clearly defined terminology is a prerequisite for any fruitful scientific discourse". Yet some words have more than one meaning, or even contradictory ones. Some key words in applied ecology and environmental affairs are so vague that they serve primarily as metaphors. Metaphors are useful of course, especially when it comes to consensus-building and transdisciplinarity. But as scientists we need to develop and agree upon definitions that allow us to work together, and point out the problems when an important word is used indiscriminately. An example is the word "Nature". Strunk and White (1979) wrote that:

Nature should be avoided in such vague expressions as "a lover of nature" and "poems about nature". Unless more specific statements follow, the reader cannot tell whether the poems have to do with natural scenery, rural life, the sunset, the untracked wilderness, or the habit of squirrels (Strunk and White 1979, p 53).

The same problems of over-extension, language "creep", and vagueness haunt phrases like the environment, ecosystem health (or well-being) and the landscape: at times the difficulty comes from the absence of a precise definition, and at times from an over-abundance of reasonably good ones. How often do we read-even in the best-edited scientific journals-that something happens, or has happened, "across the landscape" without any clarity provided 
about the spatial components of the space or place referred to? Now, the ecological definition of "landscape", first mapped out by Forman and Godron (1986), and chiseled further by Turner et al. (2001), is quite clear: objectively speaking, a landscape is a mosaic of connected and interacting ecosystems for which the spatial scale needs to be made explicit. Yet we must recall that only a small minority of those interested in the science and practice of sustainability have any training in ecology or other natural sciences. And therefore those who use "landscape" in the ecologists' sense just cited must contend with the fact that the word is commonly and indiscriminately used in conjunction with modifiers ranging from corporate, political, media, and moral, to gastronomic, not to mention the subjective notion of "landscape" as used by artists, art historians, novelists, and geographers (Aronson and Le Floc'h 1996a, b, c; Harris 2010; Wu 2010b, 2011).

Wu and Hobbs (2007) also suggest that there is a geographical divergence between what they perceive as the European and North American approaches to landscape ecology. The former group seems to accept or embrace the more subjective approach, while the latter puts more emphasis on the objective aspects and attributes of landscapes. Yet, let's face it: landscapes are objective and subjective at the same time. With landscape, as with nature, we encounter an innate, inescapable plurality of meanings that should not be ignored.

A compelling commentary on this was presented by the French geographer Berque (1984), who emphasized that landscapes are objects that are subjective and objective at the same time. This observation has merit because it can help in the search for inter- and transdisciplinarity, in the search for sustainability, and the development of a transdisciplinary science to help us get there.

"Landscape as imprint-Landscape as matrix" is the way Berque (1984) described the duality. In other words, landscapes-with very rare exceptions of course, near the North pole, and the tops of remote mountains for example-are what people have inherited from previous generations of people, generations who left their mark-or imprint-often very directly and indelibly. Yet he adds that, simultaneously landscapes are also the "matrix" or "womb" that conditions how people act, sculpt, interact with, and even actively create their world.
In restoration ecology, communication is also hindered by nomenclatural problems regarding the term restoration itself! Here's a telling anecdote from my colleague Dean Apostol, a professional practitioner and leading author in the field: "I attended the 8th annual meeting of the Urban Ecosystem Research Consortium in Portland this week. It's a 1 day affair that brings together people who are involved in stewardship of "natural" areas in and around cities of the Pacific Northwest. We had a record 500 participants. The presentations were a hodgepodge of habitat enhancement, environmental remediation, environmental education, community outreach, monitoring, and here and there something that would qualify as restoration" (D. Apostol, pers. comm., 27 Jan 2011).

What surprised and disturbed Apostol was that the entire discussion was conducted as if all these heterogeneous projects were "the same"-restoration projects-without any attempt to define what that term means. Apostol, like myself, uses the definition promulgated by the Society for Ecological Restoration (SER). The SER Primer (Society for Ecological Restoration (SER) Science and Policy Working Group 2004) offers a very concrete and clear definition of ecological restoration that is widely cited, but also widely ignored. The problem is that the field is exploding and yet only a small portion of the people working in it is aware of the SER Primer, and only an even smaller number attempts to adhere to its principles.

In the same spirit, we need to define sustainability science, and to ask how we can use it to achieve the transition to sustainability. According to the US National Academy of Sciences report on the subject (Clark and Dickson 2003), sustainability science is a vast field, surveying - in a scientific fashion-all the interactions of humans and our environment, and our ability to keep those interactions along sustainable trajectories. Kates et al. (2001) proposed seven "core questions of sustainability". To wit: "How can today's relatively independent activities of research, planning, monitoring, assessment, and decision support be better integrated into systems for adaptive management and societal learning at landscape, bioregional, and higher spatial levels?" That question goes beyond the classic scientific task of describing a situation or a problem and nudges us towards collective management inspired by the search for sustainability.

That brings me to a sixfold, or six-petaled approach to sustainability science which I've drawn 
as a monocotyledonous flower in Fig. 1. I argue that conservation ecology, landscape ecology, and restoration ecology are essential and indeed converging allies in nature conservation and landscape management efforts, and indeed that the intellectual and academic walls between them are dissolving. In the coming years, the purposefulness, commitment, and communication skills of all three groups and fields must be honed and reconciled if the emerging science of sustainability is to have vigor and success. Furthermore, we also need to clarify the interrelationships between the upper three "petals" of the "flower" depicted in Fig. 1, and those relationships already existing, or potentially to be found, among the three synergistic areas of social sciences, and societal behavior (Fig. 1, bottom), namely ecological economics, environmental law, and environmental ethics. It should be noted that in fact these three fields are themselves all part of much bigger fields, namely economics, law, and ethics sensu lato or sensu latissimo. The search for sustainability is really about

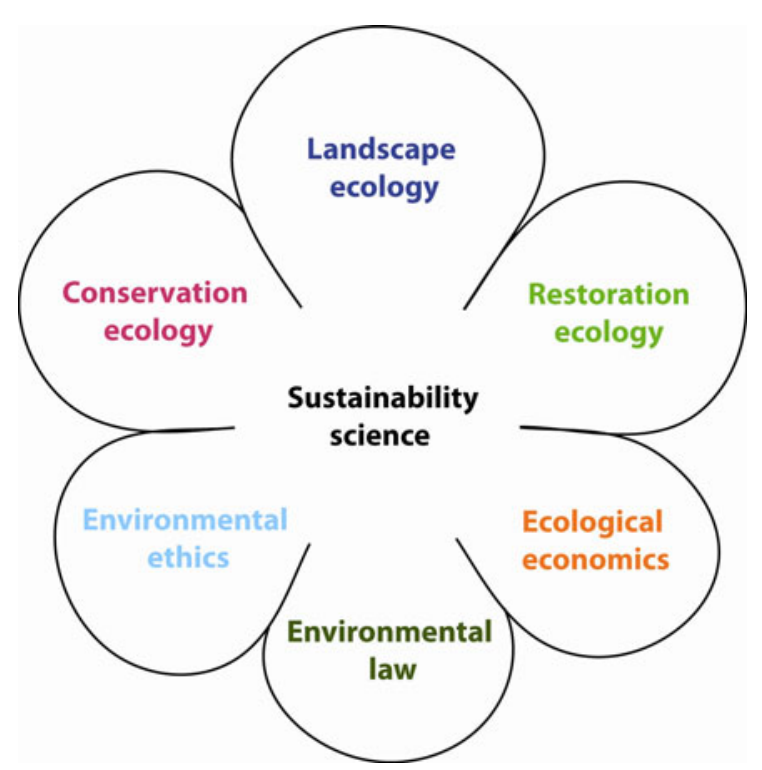

Fig. 1 Six-petaled flower for The Science of (and Search for) Sustainability. The upper three petals are about science and engineering, while the lower petals are about where we as a society want to be, and the social means to get there. Ethics, economics, and laws ideally combine to inform and refine the policies and jurisprudence governing our collective behavior. Science and engineering will be required in areas of management, conservation, sustainable use of resources and restoration of degraded ecosystems the core decisions that society takes, and imposes on itself, in all social as well as environmental domains.

The search for how to consciously and steadily make a transition towards sustainability will no doubt require inter- and transdisciplinarity, as Jianguo $\mathrm{Wu}$ noted (Wu 2006), something which is also called consilience, or the willful, intellectual "jumping together" of the practitioners of disparate sciences (Wilson 1998), each with their own terminology, methodology and mores. Terminology and nomenclature are just the tip of the iceberg. Happily, more and more examples exist to show consilience is possible. One is the new field of neuroethics, a confluence of neuroscience and philosophy (see Gazzaniga 2005; Levy 2007, for introductions). Another example, I would argue, is the holistic approach to ecological restoration proposed by Clewell and Aronson (2007) and the still broader field of restoring natural capital described in Aronson et al. (2007).

Sam Harris's book, The Moral Landscape, has a passage in the Introduction where he writes: “...human well-being entirely depends on events in the world and on states of the human brain; consequently there must be scientific truths to be known about it" (Harris 2010, p 2). Thus, there is similarity, or commonality at some level, between landscape, nature, and human wellbeing-all are objective and subjective at the same time. That is an insight that could contribute to consilience and, even to moving beyond consilience to something else, for which we don't yet have a good name. We need a name for it, however; recognizing that no one discipline will be enough to meet the challenges we face is good, but we must go further. As Costanza et al. (2006) have noted, what we need to find is the road to a sustainable and desirable future.

We need a word that describes what happens when scientists and engineers and technicians of all special trades, and all the vast array of thoughtful, experienced and committed "practitioners" (farmers, foresters, etc.), talk and above all work together to address problems of sustainability. The term "transdisciplinarity" doesn't fill the bill, nor does "consilience" (Tress et al. 2005). How do we pass from analysis, discussion and reflection to action? Given the breadth, depth, and urgency of the task at hand, let's get to work on clarifying definitions so we can communicate in a common language, and thus build a consensus, motivate action, and move forward towards sustainability. 
Acknowledgments Many thanks indeed to my friend Jianguo $\mathrm{Wu}$, for his invitation to submit this editorial, and for helpful comments. I also send thanks, and a bouquet of lilies, to Eugene Turner, Michael Weinstein, Paddy Woodworth, Jelte van Andel, Christelle Fontaine, Dean Apostol, and Andre Clewell, for their stimulating comments and critique on previous versions of the manuscript.

\section{References}

Aronson J, Le Floc'h E (1996a) Que faire de tant de notions du paysage? Natures, Sciences, Sociétés 4:264-266

Aronson J, Le Floc'h E (1996b) Vital landscape attributes: missing tools for restoration ecology. Restor Ecol 4:377-387

Aronson J, Le Floc'h E (1996c) Hierarchies and landscape history: dialoging with Hobbs and Norton. Restor Ecol 4:327-333

Aronson J, Milton SJ, Blignaut J (eds) (2007) Restoring natural capital: science, business and practice. Island Press, Washington

Berque A (1984) Paysage-empreinte-paysage matrice. L'espace géographique 12:3-4

Clark WC, Dickson NM (2003) Sustainability science: The emerging research program. Proc Natl Acad Sci USA 100:8059-8061

Clewell AF, Aronson J (2007) Ecological restoration: principles, values, and structure of an emerging profession. Island Press, Washington

Costanza R, Mitsch WJ, Day JW Jr (2006) Creating a sustainable and desirable New Orleans. Ecol Econ 26:317-320

Forman RTT (1990) Ecologically sustainable landscapes: The role of spatial configuration. In: Zonneveld IS, Forman RTT (eds) Changing landscapes: an ecological perspective. Springer-Verlag, New York, pp 261-278

Forman RTT, Godron M (1986) Landscape ecology. Wiley, New York

Gazzaniga MS (2005) The ethical brain. Dana Press, New York

Harris S (2010) The moral landscape: how science can determine human values. Free Press, New York

Kates RW, Clark WC, Corell R, Hall JM, Jaeger CC, Lowe I, McCarthy JJ, Schellnhuber HJ, Bolin B, Dickson NM, Faucheux S, Gallopin GC, Grubler A, Huntley B, Jager J,
Jodha NS, Kasperson RE, Mabogunje A, Matson P, Mooney H, Moore B III, O'Riordan T, Svedlin U (2001) Environment and development: sustainability science. Science 292:641-642

Levy N (2007) Neuroethics. Cambridge University Press, New York

Musacchio LR (2009) The scientific basis for the design of landscape sustainability: a conceptual framework for translational landscape research and practice of designed landscapes and the six Es of landscape sustainability. Landscape Ecol 24:993-1013

Musacchio LR (2011) The grand challenge to operationalize landscape sustainability and the design-in-science paradigm. Landscape Ecol 26:1-5

Naveh Z (2007) Landscape ecology and sustainability. Landscape Ecol 22:1437-1440

Society for Ecological Restoration (SER) Science and Policy Working Group (2004) The SER International Primer on Ecological Restoration. www.ser.org \& Tucson: Society for Ecological Restoration International

Strunk W Jr, White EB (1979) The elements of style, 3rd edn. MacMillan, New York

Tress G, Tress B, Fry G (2005) Clarifying integrative research concepts in landscape ecology. Landscape Ecol 20:479-493

Turner MG, Gardner RH, O'Neill RV (2001) Landscape ecology in theory and practice: pattern and process. Springer, New York

Wilson EO (1998) Consilience: the unity of knowledge. A.A. Knopf, New York

Wu J (2006) Landscape ecology, cross-disciplinarity, and sustainability science. Landscape Ecol 21:1-4

Wu J (2010a) Urban sustainability: an inevitable goal of landscape research. Landscape Ecol 25:1-4

Wu J (2010b) Landscape of culture and culture of landscape: does landscape ecology need culture? Landscape Ecol 25:1147-1150

Wu J (2011) Integrating nature and culture in: landscape ecology. In: Hong S-K, Wu JG, Kim J-E, Nakagoshi N (eds) Landscape ecology in Asian cultures. Springer, Tokyo, pp 301-321

Wu J, Hobbs RJ (2007) Landscape ecology: the state of the science. In: Wu J, Hobbs RJ (eds) Key topics in landscape ecology. Cambridge University Press, Cambridge, pp 271-287 